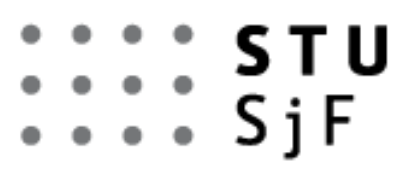

\section{Journal of MECHANICAL ENGINEERING - Strojnícky časopis}

VOLUME 66, NO 2, 2016

pp. $117-124$

DOI:10.1515/scjme-2016-0026

\title{
COMPUTATIONAL FLUID DYNAMICS ANALYSIS OF AN EVAPORATIVE COOLING SYSTEM
}

\author{
KAPILAN N. ${ }^{1}$, MANJUNATH GOWDA M. ${ }^{2}$, MANJUNATH H. N. ${ }^{2}$ \\ ${ }^{I}$ NagarjunaCollege of Engineering and Technology, Bengaluru - 562 164, India, e-mail: \\ kapil_krecmech@yahoo.com \\ ${ }^{2}$ Nitte Meenakshi Institute of Technology, Bengaluru - 560 064, India
}

\begin{abstract}
The use of chlorofluorocarbon based refrigerants in the air-conditioning system increases the global warming and causes the climate change. The climate change is expected to present a number of challenges for the built environment and an evaporative cooling system is one of the simplest and environmentally friendly cooling system. The evaporative cooling system is most widely used in summer and in rural and urban areas of India for human comfort. In evaporative cooling system, the addition of water into air reduces the temperature of the air as the energy needed to evaporate the water is taken from the air. Computational fluid dynamics is a numerical analysis and was used to analyse the evaporative cooling system. The CFD results are matches with the experimental results.
\end{abstract}

KEYWORDS: Cooling, evaporation, pads, CFD, analysis

\section{Introduction}

An evaporative cooling system is a device that cools air through the evaporation of water which reduces the temperature of the air. The air which is cooled by the evaporation of water consumes less energy than the refrigeration. In dry weather conditions, evaporative cooling of air has added advantage over air-conditioner, as it increases the humidity which increases the comfort of building occupants. The cooling effect of evaporative cooling system dependent on the difference between the wet-bulb and dry-bulb temperatures. In arid climates, this type of system can be an alternative to vapour compression based cooling system. In non-arid climates an indirect evaporative cooling system can be used without increasing the humidity and hence it has an advantage over the direct evaporative cooling system [1]. In summer, cooling system is in demand as it provides thermal comfort to humans. An evaporative cooling system is one of the cheapest cooling systems and hence it is most popular. Faten et al proposed a control system for the evaporative cooling system used in greenhouse cooling system. They developed a temperature controller to control the air volume flow rate in padfan evaporative cooling system and to maintain indoor temperature of $20^{\circ} \mathrm{C}$ and relative humidity of $70 \%$. The humidity controller operates between humidify and dehumidify modes to add the moisture to the air by humidification and to remove the excess atmospheric moisture accumulating within the green- house. For the continuous operation of the greenhouse, they developed a control technique and used a computer model based on commercial software, to determine the temperature and relative humidity inside the greenhouse [2].

Figure 1 shows the working principle of an evaporative cooling system. In an evaporative cooling system, dry unsaturated air is pulled through a cooling pad which is wetted by water spray, the water is evaporated and is absorbed into air as water vapour. The 
process takes place by increasing the humidity in the air and decreasing the indoor dry bulb temperature and make indoor system cool.

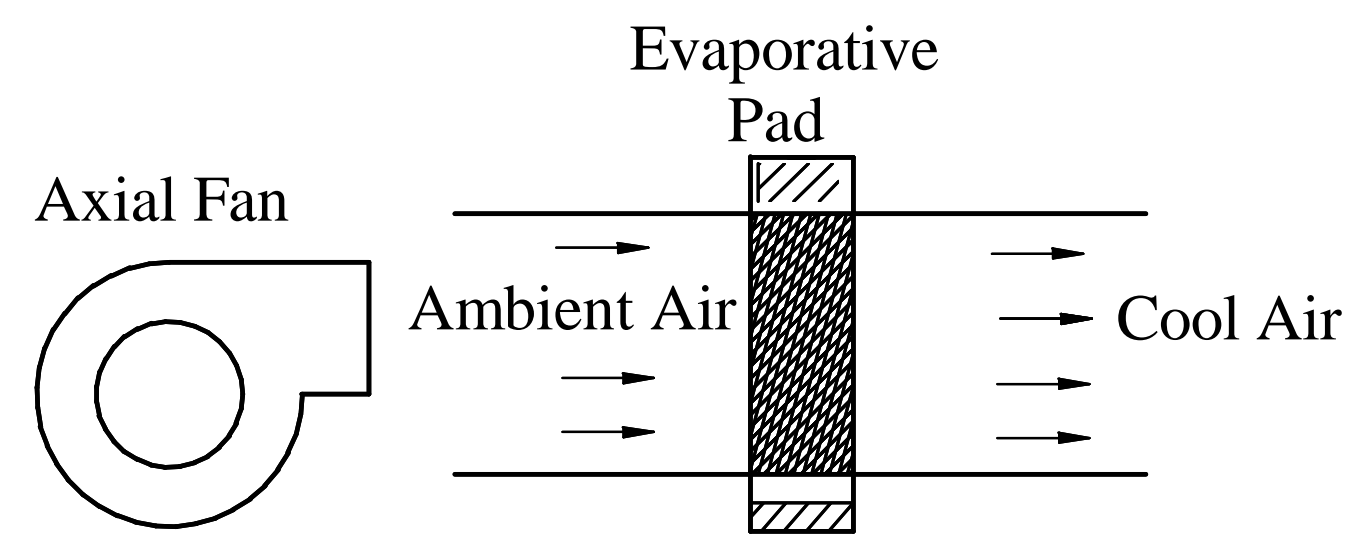

Fig. 1 Evaporative Cooling System

In recent years, computers are most widely used in computational and simulation work as it can perform the millions of calculations required to simulate the fluid flow problems related to Mechanical engineering. The computational fluid dynamics (CFD) is a computerbased tool that uses numerical methods and algorithms to solve and analyze problems that involve fluid flows, heat transfer and other similar physical problems. In practice, CFD is very effective in the early elimination of competing design configurations. The CFD is not a substitute for experimentation, but a very powerful additional problem solving tool. The commercially available CFD packages uses sophisticated user interfaces to input problem parameters and to examine results. All CFD software's contain three main elements such as Pre-processor, Solver and Post processor.

Sapounas et al carriedout simulation of the greenhouse equipped with a fan and pad evaporative cooling system using CFD considering both the external and internal climatic conditions. They validated the CFD results with the experimental data based on the greenhouse inside air temperature. Their results indicated that the proper selection of ventilation rate is important to improve the efficiency of evaporative cooling systems in greenhouses [3]. Franco et al carried out an computational fluid dynamics analysis of corrugated cellulose evaporative cooling pads that are most widely used in Mediterranean greenhouses and the simulation reading are similar to the experimental results. They determined the pressure drop produced by the cooling pads at different water flows and wind speeds. They suggested that CFD is a suitable tool for the modelling and simulation of evaporative pads [4].

Jiaoliao Chen et al used a CFD model to simulate the greenhouse adopting the fan-pad cooling system in summer and to findout the distribution of air velocity and temperature. The reported that the variation in CFD and experimental results of air temperature was between 0.9 to $4^{\circ} \mathrm{C}$ and the variation in air velocity was less than $0.15 \mathrm{~m} / \mathrm{s}$. From the work, they conclude that the CFD can be used as a tool for fan-pad evaporative cooling system used in the greenhouse [5]. Sapounas et al carriedout the simulation of the greenhouse equipped with fan and pad evaporative using a CFD code in terms of heat and mass transfer and both the external and internal climatic conditions. They used porous medium approach to simulate the crop. They used Reynolds-averaged Navier-Stokes equations for the numerical analysis. The results shows that the CFD can be used as a tool to improve the system efficiency of the evaporative cooling system for greenhouses [6]) 
Kulkarni et al carriedout the design, installation and analysis of rooftop ventilators in a classroom of an educational institute which is located in a hot and arid climatic zone of Nashik, India. The performance of the rooftop ventilators was evaluated when the rooftop ventilators are working, rooftop ventilators are working with windows openings covered with wetted wood wool pads used for evaporative cooling and when rooftop ventilators are not working. The researchers reported that the temperature drop of 6.1 degree $C$ can be achieved with wetted evaporative wood wool pads [7]. Vahid et al studied the feasibility of using a hybrid system of ground heat exchangers and direct evaporative cooling system in arid weather condition. Their simulation results show that the comfort condition can be achieved with the hybridization of Ground Coupled-Circuit and Direct Evaporative Cooler. However it cannot be achieved with direct evaporative cooler alone. They also reported that the effectiveness of a hybrid system is more than unity and suggested that the hybrid system can be a replacement to conventional vapour compression systems. This hybrid system also reduces the electrical energy consumption [8]. Few researchers [9,10] have successfully carried-out computational fluid dynamics analysis in heat transfer problems.

\section{$2 \quad$ Materials and methods}

The computational fluid dynamics is a powerful computational tool which is most widely used for the simulations of all levels of complexity. Hence in this work, a computational analysis was carried out with help of commercial CFD software, ANSYS CFX to study the flow pattern of the fluid in the evaporative pads. The ANSYS CFX is available within the ANSYS Workbench platform and has several advantages for data and information common to many simulations. It uses the advanced technology with an algebraic multi-grid solver and efficient parallelization which gives the solutions quickly. The CFX analysis gives users the power to extract any desired quantitative data from the solution. An evaporative cooling system was developed and tests were conducted to validate the results of the CFD work.

\section{Experimental setup}

The experimental set up of direct evaporative cooling system consists of a rectangular wind tunnel, axial exhaust fan fixed at inlet of tunnel, evaporative pad and necessary instrumentation to record the observations. The evaporative pad was kept in the wind tunnel. A non-contacting tachometer was used to measure the speed of the exhaust fan and the speed of the fan were adjusted by speed control knob. A 20 liter water tank was used to supply the water to the evaporative cooling system through the nozzles which was placed above the evaporative pads. A U Tube water manometer was used to the pressure drop across the evaporative cooling pad. An energy meter was used to find out the power consumed by the fan. Thermometers were used to measure the wet bulb and dry bulb temperatures of the air at the inlet and outlet of the tunnel. Figure 2 shows the experimental setup.

\section{$4 \quad$ Results and discussion}

The CFD analysis was carried-out successfully and results were compared with the experimental results. An evaporative cooling system was developed and tested. The experimental results were used to validate the CFD results. 


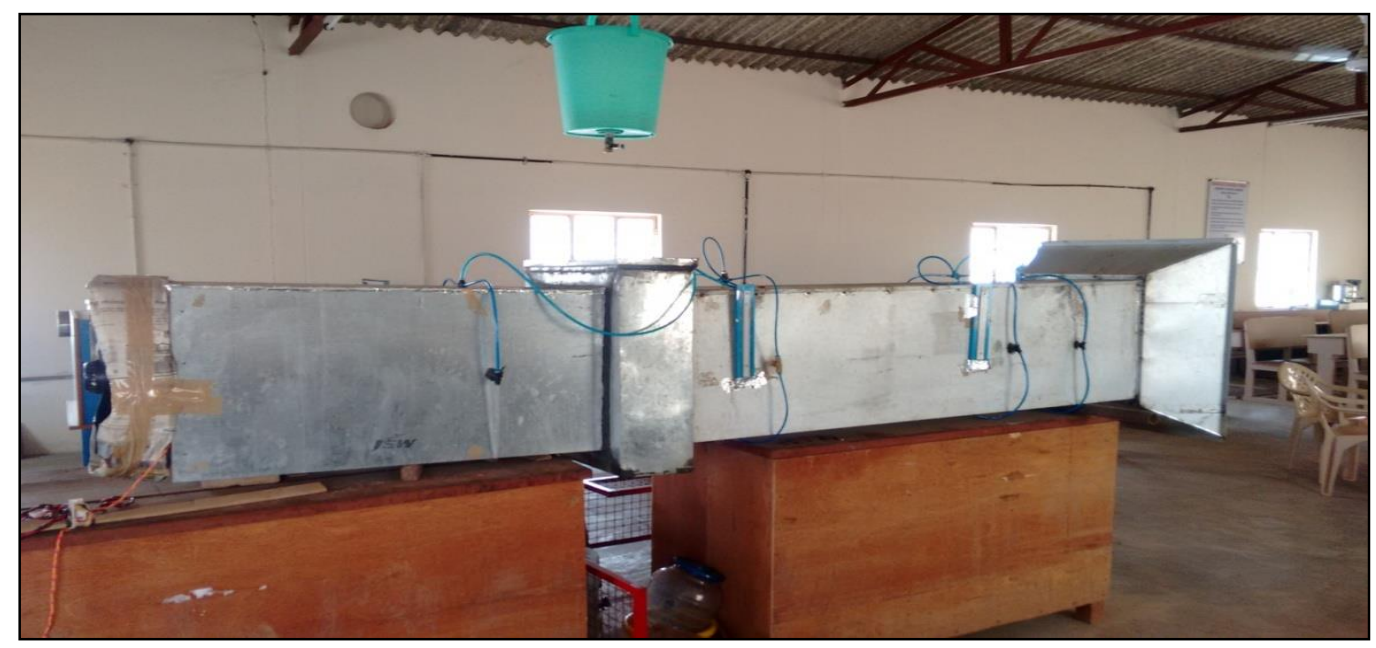

Fig. 2 Experimental setup

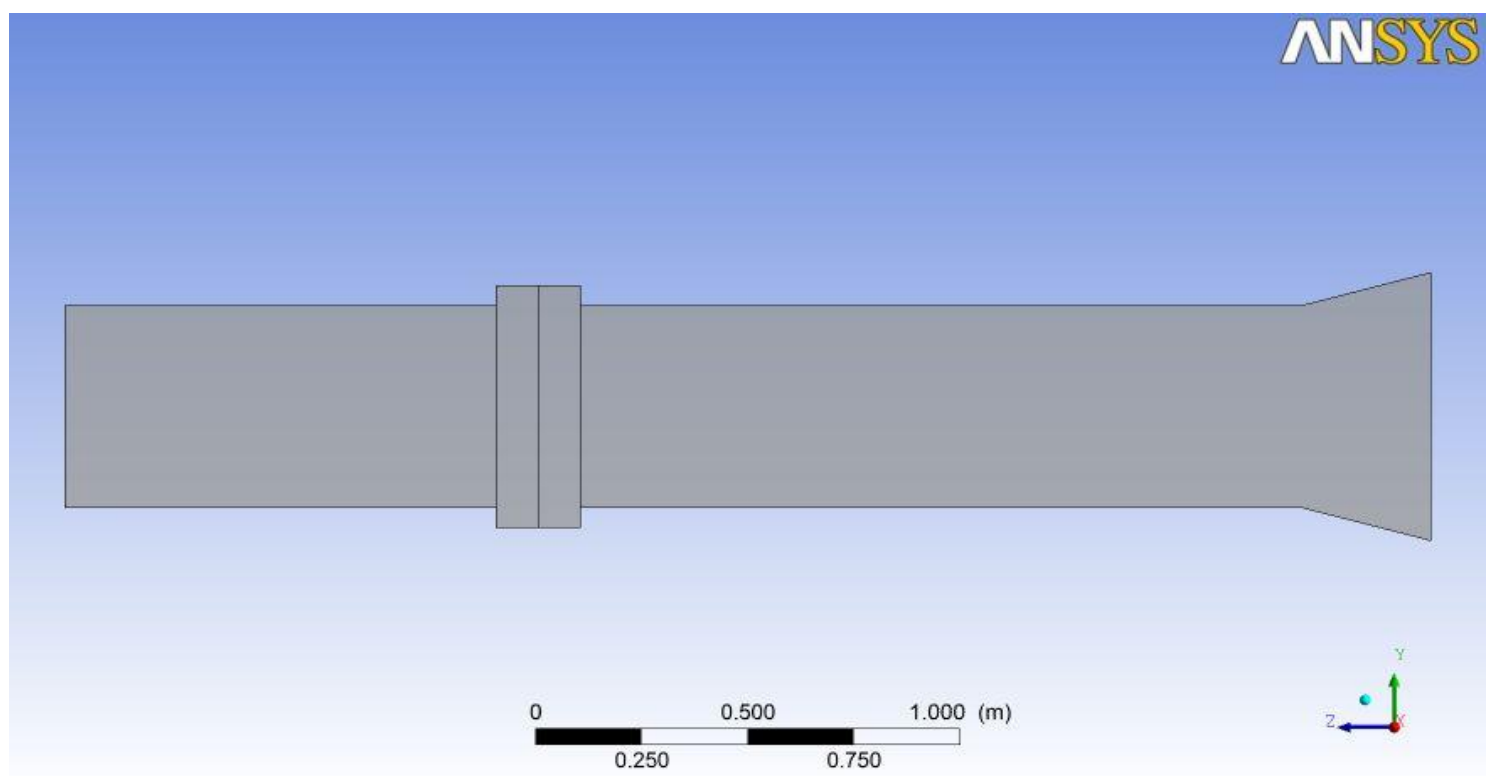

Fig. 3 Model of Evaporative Cooling System

Figure 3 shows the model of the evaporative cooling system developed using the ANSYS tool. Figure 4 shows the meshed model in ANSYS ICEM. The mesh was done to whole geometry of the system.

Figure 5 shows the pressure distribution across the evaporative cooling system. The pressure at the inlet of tunnel is above atmospheric due to fan speed and is equal to 1.316 bar. As the flow takes place through the tunnel the pressure of the flow reduces. However the pressure drops takes place at the cooling pad and the pressure at the pads is equal to $1.117 \mathrm{bar}$. The pressure of the flow reduces further and is just above the atmospheric pressure at the outlet of the cooling system. $\mathrm{s}$ and it moves in normal pressure close to atmospheric pressure towards the outlet of the tunnel. However the pressure at the divergent nozzle and again drops in nozzle due to wood plate with three small holes made for the outlet air. 


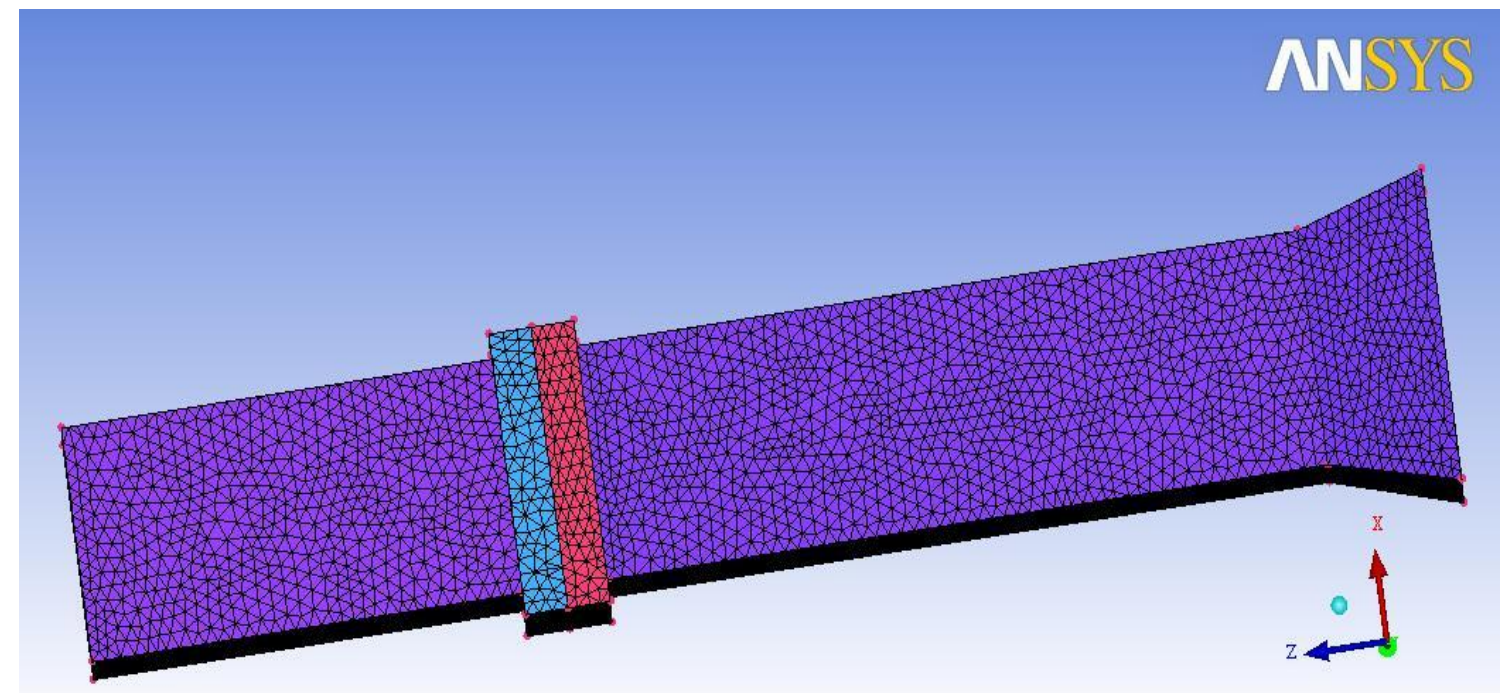

Fig 4 Meshed model of Evaporative Cooling System

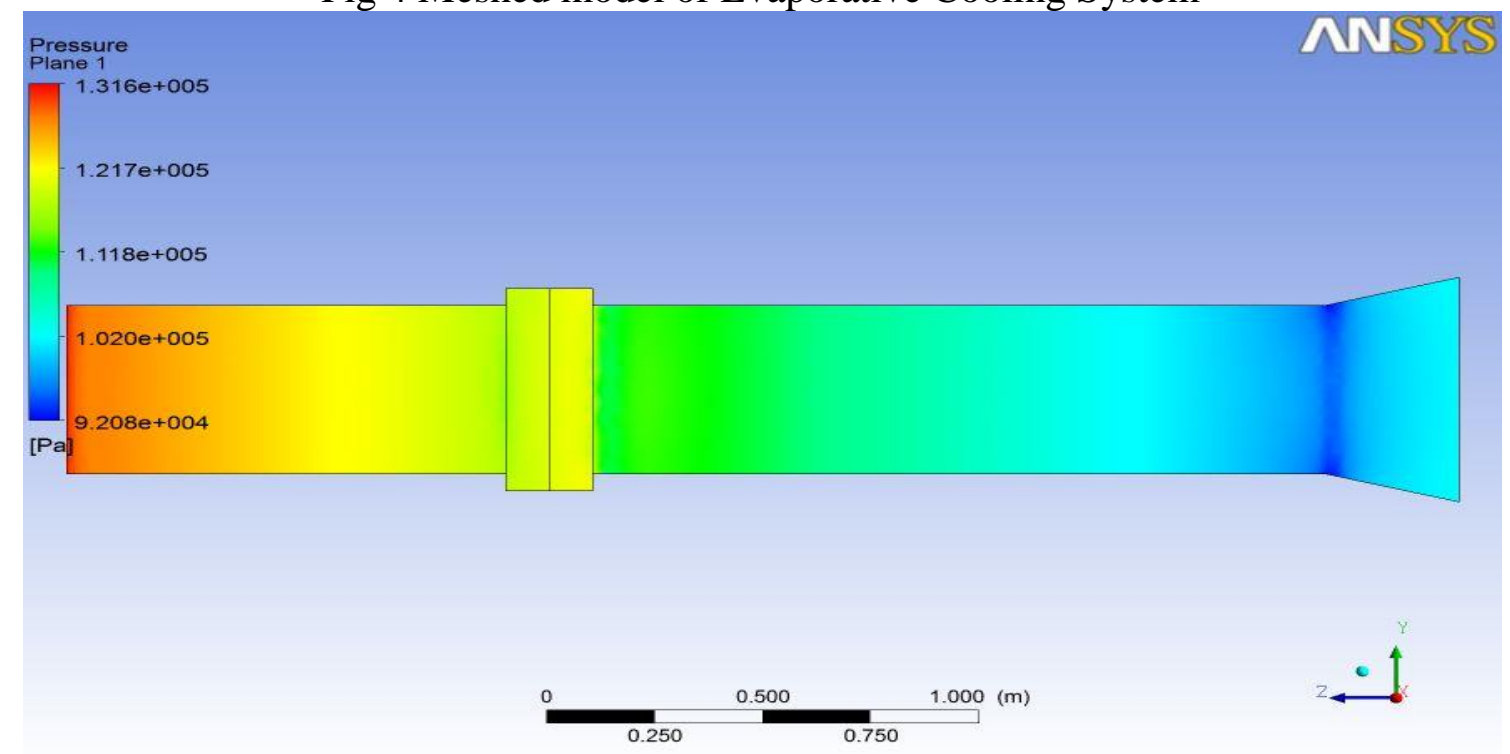

Fig. 5 Pressure plane of double pad cooling system

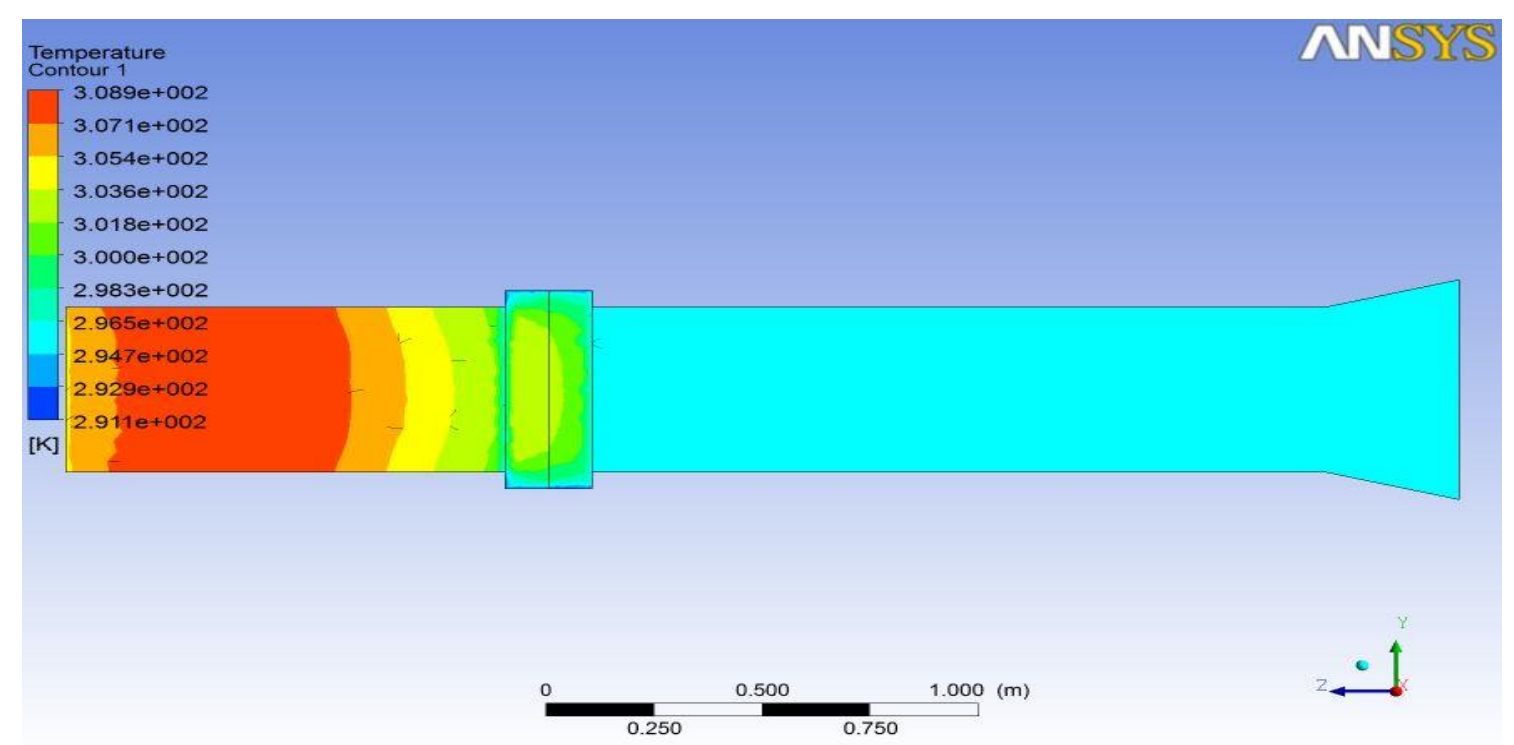

Fig. 6 Temperature counter of double pad cooling system

Volume 66, No. 2, (2016) @2016 SjF STU Bratislava 


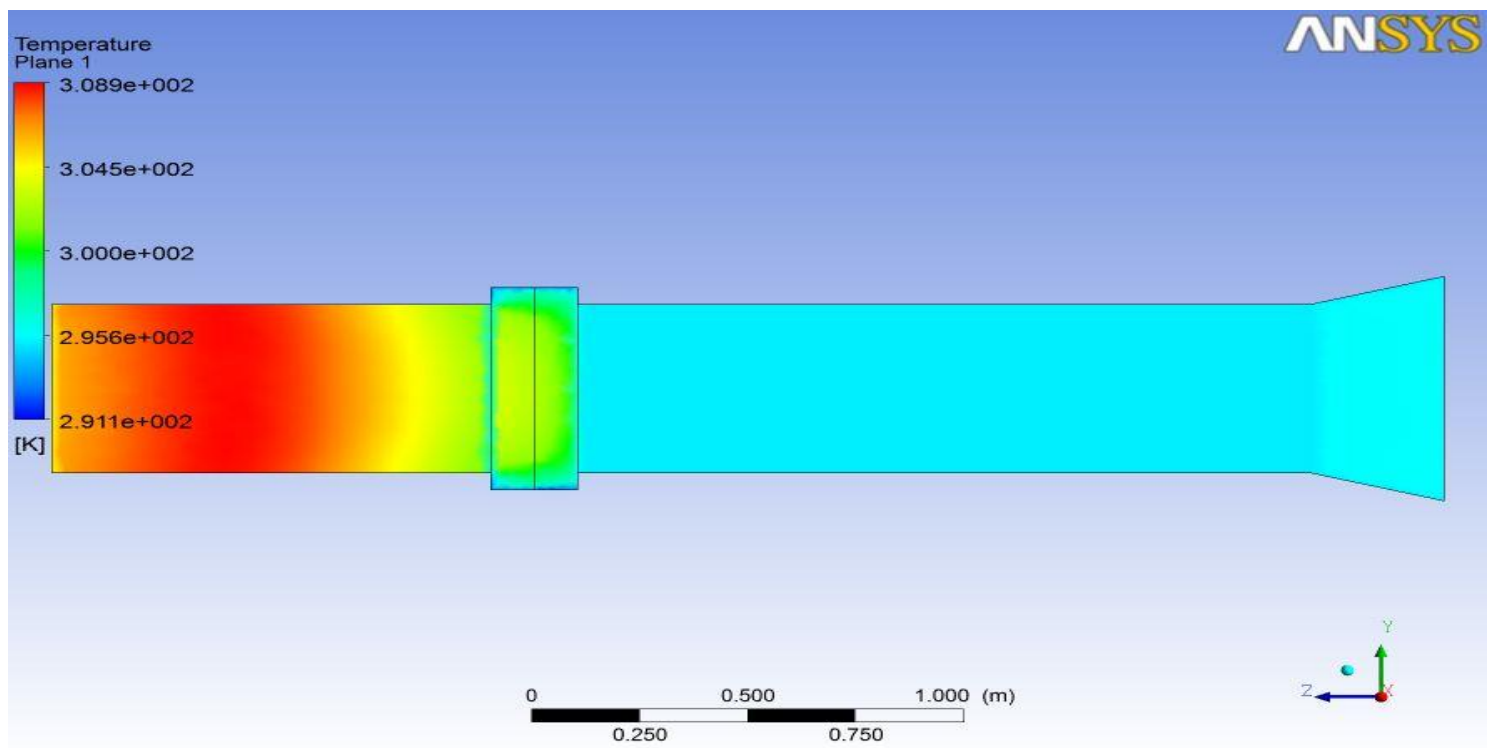

Fig. 7 Temperature plane of double pad cooling system

Figures 6 and 7 shows temperature variations in the double pad inserted cooling system. Inlet temperature is $31^{\circ} \mathrm{C}$ and it decreases to $25^{\circ} \mathrm{C}$.

\section{$5 \quad$ Analysis of double celder pad for increased speed}

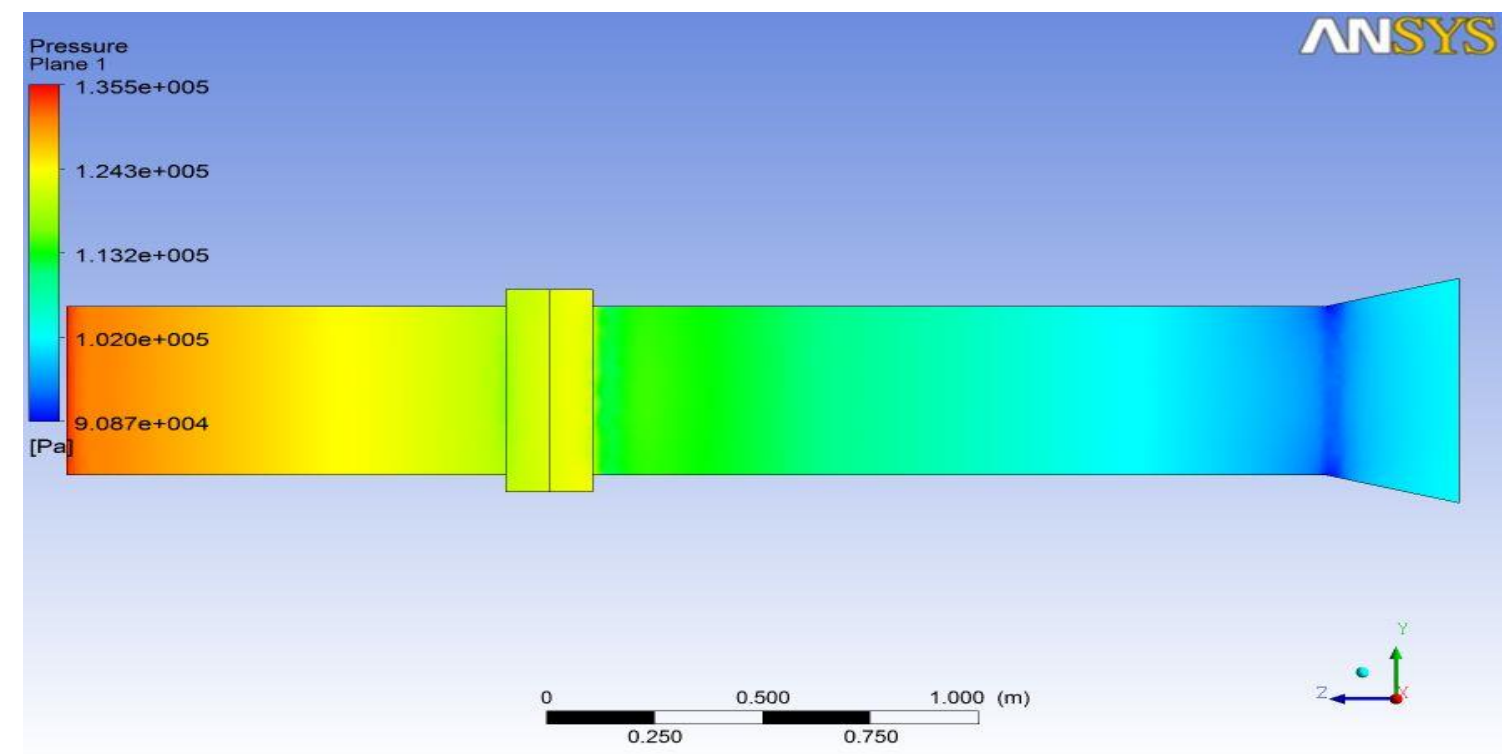

Fig. 8 Pressure plane of double pad celdek cooling system for increased speed

Figure 8 shows as the speed increases, inlet pressure also increases. Inlet pressure is 1.355 bars. Pressure drops in the pad to 1.132 bars. 


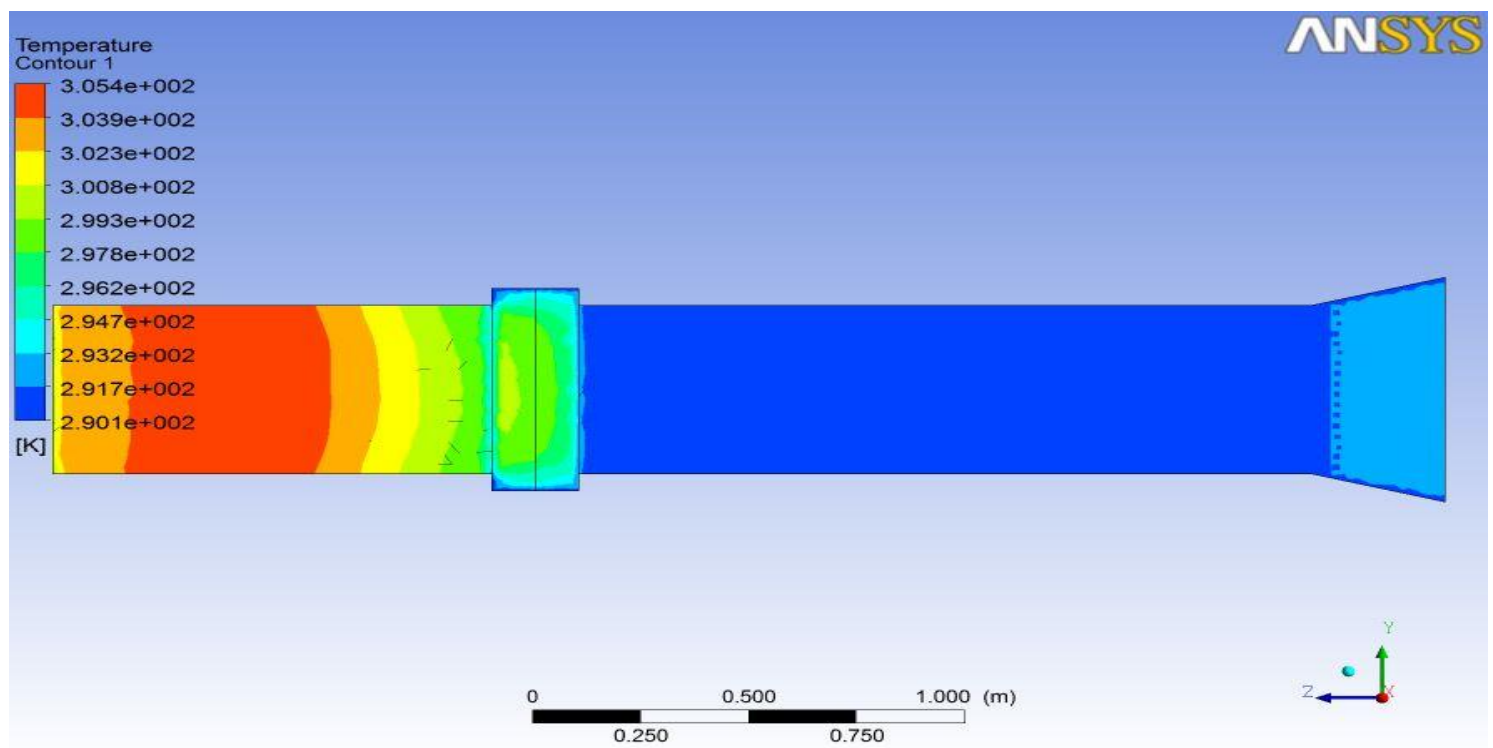

Fig. 9 Temperature counter of double pad celdek cooling system for increased speed

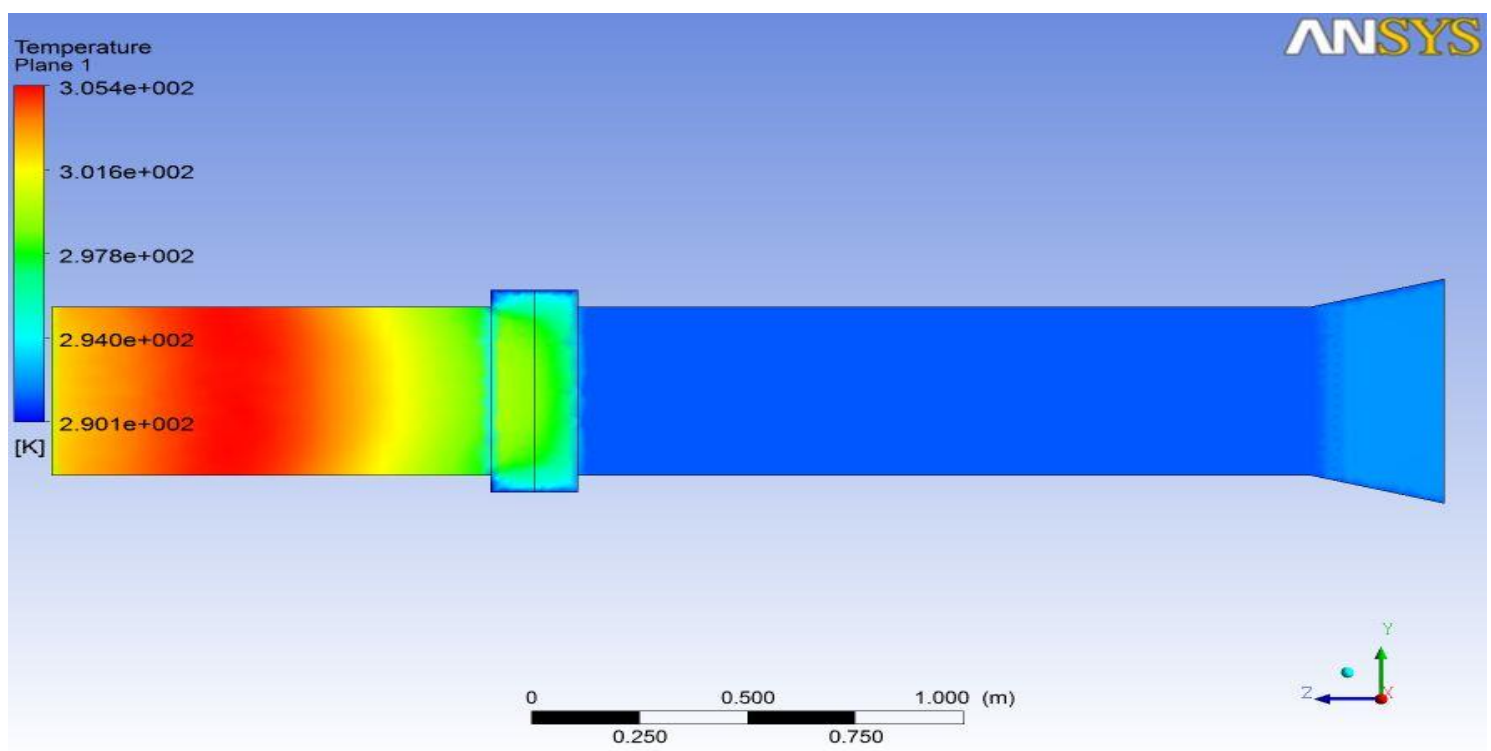

Fig. 10 Temperature plane of double pad celdek cooling system for increased speed

Figure 9 and 10 shows temperature variations in the system. Inlet temperature $28{ }^{\circ} \mathrm{C}$ increases to $32{ }^{\circ} \mathrm{C}$ due to fan speed and at the end decreases to $20^{\circ} \mathrm{C}$.

\section{Comparison of CFD and experimental results}

Table 1 compares the CFD and experimental results. From the table it is observed that the percentage error of theoretical calculation values and Computational one is well within the range. This shows the compatibility of Theoretical calculation and Computational Analysis over Experiment. 
Table 1 Comparison of Experimental and CFD Results

\begin{tabular}{|c|c|c|c|}
\hline \multicolumn{2}{|c|}{ Experimental Results } & \multicolumn{2}{c|}{ CFD Results } \\
\hline $\begin{array}{c}\text { Inlet } \\
\text { Temperature } \\
\left({ }^{\circ} \mathrm{C}\right)\end{array}$ & $\begin{array}{c}\text { Outlet } \\
\text { Temperature } \\
\left({ }^{\circ} \mathrm{C}\right)\end{array}$ & $\begin{array}{c}\text { Inlet Temperature } \\
\left({ }^{\circ} \mathrm{C}\right)\end{array}$ & $\begin{array}{c}\text { Outlet Temperature } \\
\left({ }^{\circ} \mathrm{C}\right)\end{array}$ \\
\hline 31 & 25 & 31 & 24 \\
\hline
\end{tabular}

\section{CONCLUSION}

The computational fluid dynamics analysis was carried using commercially available software to analyze the temperature distribution, pressure and velocity in the evaporative cooling system. An evaporative cooling system was developed and experiments were conducted to compare the CFD results with the experimental results. From the comparison, it was observed that the CFD results are similar to the CFD results.

\section{References}

[1] www.wikipedia.com

[2] Faten Hosney Fahmy, Hanaa Mohamed Farghally, Ninet Mohamed Ahmed, A. A. Nafeh, Modeling and Simulation of Evaporative Cooling System in Controlled Environment Greenhouse, Journal of Smart Grid and Renewable Energy, 2012, 3, 67 71

[3] Sapounas, A.A., Bartzanas T., Nikita-Martzopoulou, C., and Kittas, C.: Aspects of CFD Modelling of a Fan and Pad Evaporative Cooling System in Greenhouses, International Journal of Ventilation, 2008, 6(4), 379-388.

[4] Franco, A., Valera, D.L., Peña, A., Pérez, A.M.: Aerodynamic analysis and CFD simulation of several cellulose evaporative cooling pads used in Mediterranean greenhouses, Computers and Electronics in Agriculture, 2011, 76(2), 218-230

[5] Chen, J., Cai, Y., Xu, F., Hu, H., Q.: Analysis and Optimization of the Fan-Pad Evaporative Cooling System for Greenhouse Based on CFD, Journal of Advances in Mechanical Engineering, 2014, 6, 712-740

[6] Sapounas A, Nikita-Martzopoulou, Ch, Martzopoulos, G, Numerical and Experimental Study of Fan and Pad Evaporative Cooling System in a Greenhouse with Tomato Crop, Quelle, Acta Horticulturae, 2008, 987 - 994.

[7] Kulkarni, A.B., Suryawanshi, S.D.: Effect on Comfort using Evaporative Cooling assisted Building Ventilation with Rooftop Ventilators, International Journal of Engineering Research \& Technology, 2014, 3(4), 1476- 1479

[8] Vahid Khalajzadeh, Ghassem Heidarinejad, Using Hybrid System of Ground Heat Exchanger and Evaporative Cooler in Arid Weather Condition, International Journal of Mechanical, Aerospace, Industrial, Mechatronic and Manufacturing Engineering, 2011, 5(8), 2011, 1610-1615

[9] Arafat, A., Bhuiyan, A. K. M, Sadrul Islam: CFD analysis of different fin-and-tube heat exchangers, Journal of Mechanical Engineering - Strojnicky časopis, 2011, 62(4), 237241

[10] Lin Zhu, Tien-Chien Jen, Yi-Hsin Yen, Cheng-Long Yin, Mei Zhu: Numerical investigation of heat pipe cooling in drilling applications, Journal of Mechanical Engineering - Strojnícky časopis, 2010, 61(4), 233-239 